\title{
Dynamic Stability of Cylindrical Shells under Moving Loads by Applying Advanced Controlling Techniques-Part II: Using Piezo-Stack Control
}

\author{
Khaled M. Saadeldin Eldalil ${ }^{1}$ and Amr M. S. Baz ${ }^{2}$ \\ ${ }^{1}$ Department of Mechanical Engineering, Tanta University, Sperbay, Tanta, Egypt \\ ${ }^{2}$ Department of Mechanical Engineering, University of Maryland, College Park, MD 20742, USA
}

Correspondence should be addressed to Khaled M. Saadeldin Eldalil, eldalil01@msn.com

Received 2 April 2009; Accepted 6 July 2009

Recommended by Mohammad Tawfik

The load acting on the actively controlled cylindrical shell under a transient pressure pulse propelling a moving mass (gun case) has been experimentally studied. The concept of using piezoelectric stack and stiffener combination is utilized for damping the tube wall radial and circumferential deforming vibrations, in the correct meeting location timing of the moving mass. The experiment was carried out by using the same stiffened shell tube of the experimental $14 \mathrm{~mm}$ gun tube facility which is used in part 1. Using single and double stacks is tried at two pressure levels of low-speed modes, which have response frequencies adapted with the used piezoelectric stacks characteristics. The maximum active damping ratio is occurred at high-pressure level. The radial circumferential strains are measured by using high-frequency strain gage system in phase with laser beam detection system similar to which used in part 1. Time resolved strain measurements of the wall response were obtained, and both precursor and transverse hoop strains have been resolved. A complete comparison had been made between the effect of active controlled and stepped structure cases, which indicate a significant attenuation ratio especially at higher operating pressures.

Copyright ( $) 2009$ K. M. S. Eldalil and A. M. S. Baz. This is an open access article distributed under the Creative Commons Attribution License, which permits unrestricted use, distribution, and reproduction in any medium, provided the original work is properly cited.

\section{Introduction}

The production of long slender gun systems to meet increased exit velocity requirements of rounds has subsequently increased the effect of precision and accuracy of firing as well as barrel/round interactions during firing. A lightweight, low-cost method is desired to damp the induced vibrations thereby increasing performance of the gun system.

Some experimental and theoretical methods are suggested for damping and controlling vibrations in the gun tubes. A relatively inexpensive and lightweight method of damping vibrations in some structures is to apply a surface treatment of a viscoelastic material and a constraining layer, as a passive control combination [1], which deals with the transverse vibrations in the system resulted in shear deformation of the viscoelastic material, which in turn dissipates the energy. This technique is very effective for damping terrain and firing-induced vibrations and hence increases precision and accuracy.
The integration of viscoelastic damping materials into various structures has been widely theoretical studied. EulerBernoulli beam theory has been used to model viscoelastic materials using the Rayleigh Ritz approximation for damping. Timoshenko beam theory incorporates both shear deformation and rotational deformation in the formulation. The modal strain energy method [2] makes use of the relationship between damping factors and modal loss factors in order to assign damping factors to real elastic modes assign approximation to light damping. The Golla-HughesMcTavish (GHM) method [3, 4] uses a finite element approach where viscoelastic damping is introduced as a series of minioscillator terms and auxiliary dissipation coordinates. DiTaranto and Blasingame [5] and Mead and Markus [6] derived a sixth-order PDE to model the transverse vibrations of a three-layer beam system based on the equations developed for flexural vibrations of layered plates. In this approach damping of the viscoelastic layer is incorporated through the use of a complex shear modulus. 


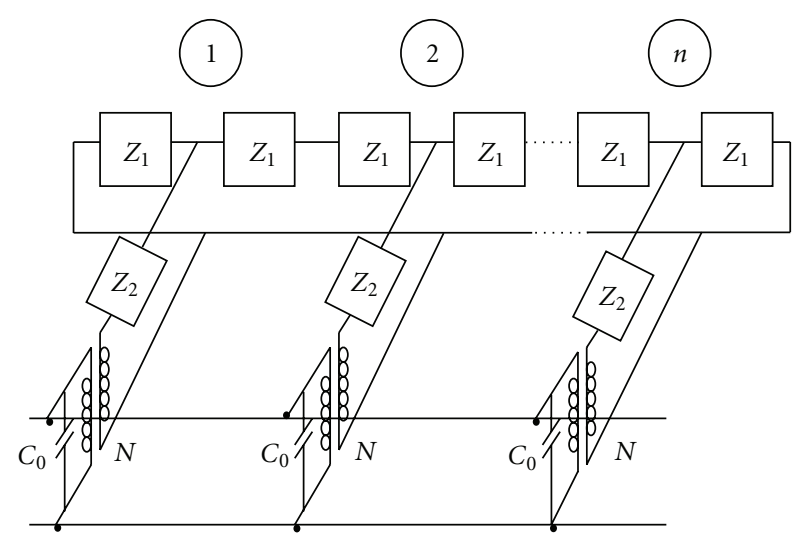

FIGURE 1: Equivalent circuit representation of a stack with the mechanical ports of each equivalent circuit representing a layer connected in series and $n$ electrical ports in parallel.

Ro et al. [7] and Sung [8] developed this technique theoretically and experimentally by applying active constrained damping layer (ACLD); they modeled the tube/ACLD system by using Golla-Hughes-McTavish method in order to predict the tube response in the time domain. They calculated the transient response using finite element method; the predicted response is compared with that of a tube controlled with passive constrained layer damping treatment. The predictions of the finite element model are validated experimentally. The results obtained indicted that ACLD treatment has achieved significant attenuation of the structure vibrations.

On the other hand, the methods for damping radial and circumferential vibrations of the shell tube walls are completely different. Using periodic stiffeners distributed on the shell tube surface is tried theoretically by Ruzzene and baz $[9,10]$, Aldareihem and Baz [11, 12], and others [13-15], and studied experimentally in part 1, Eldalil and Baz [16].

In this work, the concept of applying a feedforward control by using piezoelectric stack is experimentally tried. To the best of our knowledge, this technique is not examined before for damping the radial and circumferential deformations of the shell walls theoretically or experimentally. The selection of the piezoelectric stacks is based on its dynamic characteristics which are meeting the shell walls radial and circumferential deformation dynamic modes. A feedforward control system is suggested and designed in order to achieve the optimum attenuation ratio and satisfy suitable dynamic stability.

1.1. Piezoelectric Stack Characteristics. Piezoelectric stacks are used in variety applications that require relatively high force and larger displacement than single element piezoelectric transducers can produce. These include micropositioning systems, solid-state pumps/switches, noise isolation mounts, ultrasonic drills, and stacked ultrasonic transducers. The solution for the zero bond length stacks was derived by Martin $[17,18]$. His model was derived from Mason's equivalent circuit of $n$ layers connected mechanically in series and electrically in parallel as shown in Figure 1.
TABLE 1: The effective material properties for the data of the stack resonator.

\begin{tabular}{lcc}
\hline Property & Real & Imaginary \\
\hline$s_{33}^{E}\left(\mathrm{~m}^{2} / \mathrm{N}\right)$ & $2.00 \times 10^{-11}$ & $-3.0 \times 10^{-13}$ \\
$\varepsilon_{33}^{T}(\mathrm{~F} / \mathrm{m})$ & $3.00 \times 10^{-11}$ & $-6.17 \times 10^{-10}$ \\
$d_{33}(\mathrm{C} / \mathrm{N})$ & $3.925 \times 10^{-10}$ & $-7.66 \times 10^{-12}$ \\
$k_{33}$ & 0.5 & -0.001 \\
\hline
\end{tabular}

Martin's general solution for the admittance of a piezoelectric stack of area $A, n$ layers, and total length $n L$ is [19]

$$
Y(\omega)=i \omega n C_{0}+\frac{2 N^{2}}{Z_{S T}} \tanh \left(\frac{n \gamma}{2}\right)
$$

where

$$
\begin{gathered}
C_{0}=\frac{\varepsilon_{33}^{T} A}{L}\left(1-k^{2}{ }_{33}\right), \\
N=\frac{A d_{33}}{L s_{33}^{E}}, \\
Z_{S T}=\left[Z_{1} Z_{2}\left(2+\frac{Z_{1}}{Z_{2}}\right)\right]^{0.5}, \\
\gamma=2 \arcsin h\left[\left(\frac{Z_{1}}{2 Z_{2}}\right)^{0.5}\right], \\
Z_{1}=i \rho v^{D} A \tan \left(\frac{\omega L}{2 \nu^{D}}\right), \\
Z_{2}=\frac{\rho v^{D} A}{i \sin \left(\omega L / \nu^{D}\right)}+\frac{i N^{2}}{\omega C_{0}},
\end{gathered}
$$

and $\nu^{D}=1 / \sqrt{\rho s_{33} D}$ is the acoustic velocity at constant electric displacement. The constants $\varepsilon_{33}^{T}, s_{33}^{D}, d_{33}$ are the free permittivity, the elastic compliance at constant electric displacement, and the piezoelectric charge coefficient, respectively. Using (1) to (2), Martin demonstrated that in the limit of large $n(n>8)$, the acoustic wave speed in the material was determined by the constant field elastic constant $s_{33}^{E}\left(1 / \sqrt{\rho s_{33}^{E}}\right)$. In the limit of $n>8$ an analytical equation for the admittance was presented which allowed for direct determination of material constants from the admittance data [3]. In this limit the admittance was shown to be

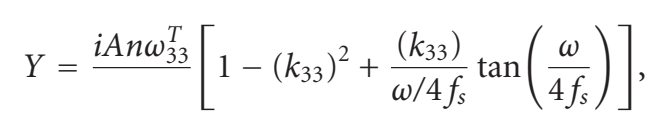

where the series resonance frequency is

$$
f_{s}=\frac{1}{2 \pi L} \sqrt{\frac{1}{\rho s_{33}^{E}}} .
$$

The effective material properties are shown in Table 1, for the data of the stack resonator shown in Figure 2. The stack length $n L=0.02 \mathrm{~m}$, Area $A=(0.01)^{2} \mathrm{~m}^{2}$, and density $\rho=7800 \mathrm{~kg} / \mathrm{m}^{3}$.

For more details, refer to [19]. 


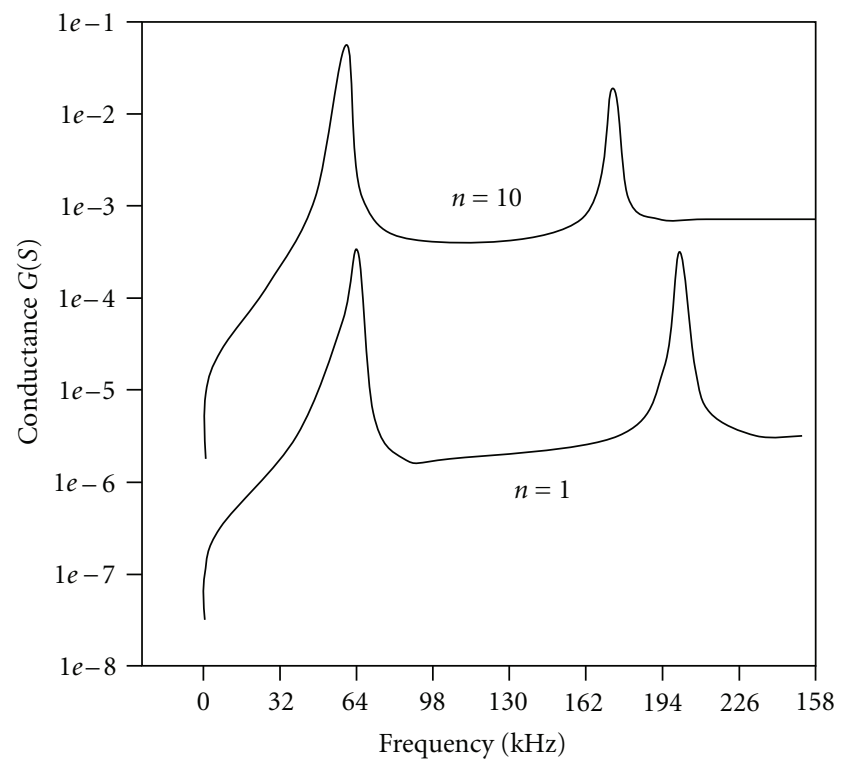

Figure 2: Typical conductance as a function of frequency for $n=1$ to 10 layers.

\section{Feedforward Control}

2.1. Concept of Feedforward Control. Feed-forward control, which is used herein, will suppress the disturbance deformations before it has had the chance to affect the system's essential variables. This requires the capacity to anticipate the effect of perturbations on the system's goal. Otherwise the system would not know which external fluctuations to consider as perturbations, or how to effectively compensate their influence before it affects the system. This requires that the control system is able to gather early information about these fluctuations. Figure 3 shows block diagram of typical feedforward control system; the effect of disturbances $D$ on the essential variables $E$ is reduced by an active regulator $R$.

Feedforward control can entirely eliminate the effect of the measured disturbance on the process output. Even when there are modeling errors, feed-forward control can often reduce the effect of the measured disturbance on the output better than that achievable by feedback control alone. However, the decision as to whether or not to use feedforward control depends on whether the degree of improvement in the response to the measured disturbance justifies the added costs of implementation and maintenance. The economic benefits of feedforward control can come from lower operating costs and/or increased salability of the product due to its more consistent quality.

2.2. Mathematical Formulation. Figure 4 shows a traditional feedforward control scheme. The transfer function between the process output $Y$ and the measured disturbance $d$ as shown in Figure 4 is

$$
Y(s)=\left(P_{d}-P q_{f f}\right) d
$$

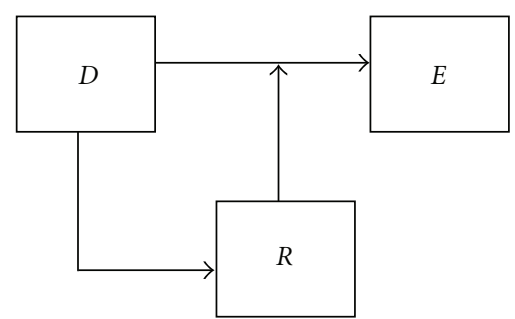

Figure 3: Basic mechanisms of regulation, from left to right: buffering, feedforward, and feedback block diagrams.

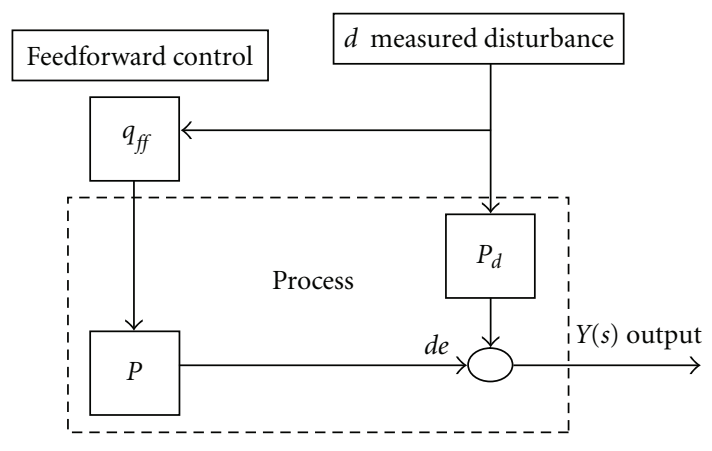

FIgURE 4: Traditional feedforward control structure.

To eliminate the effect of the measured disturbance, we need only choose $q_{f f}$ so that:

$$
\begin{aligned}
& P_{d}-P q_{f f}=0, \\
& q_{f f}=P^{\sim-1} P_{\mathrm{d}}^{\sim},
\end{aligned}
$$

where $\mathrm{a} \sim$ over a process transfer function indicates that it is a model of the process. Even in the above case, where the feedforward controller can perfectly compensate the measured disturbance, Seborg et al. [20].

\section{Experimental Setup}

The experiments were carried out with in-door Pneumatic 6/12-feet helium Gun Facility in the Vibration and Noise Control Laboratory at University of Maryland; it has a stainless steel tube length of 6 feet. The detailed description is found in part 1, Eldalil and Baz [16].

3.1. Piezoelectric Stack Configuration. The piezoelectric stack and shell tube combination is shown in Figure 5. As indicated in part 1 [16], the stiffeners are composed of three parts, two half rings (2, 3), in Figure 5, and one outer ring, surrounding the shell tube (1); consequently, in active control, the outer ring is removed and the stacks $(4,7)$ are rested on the upper and lower half rings. A stainless steel clamp strip (6) is used to hold the components fixed in position, and the screw (5) is used to create initial tension in the clamp strip and consequently generates compression force distributed around the shell tube substituting the removed outer ring of the stiffener. 


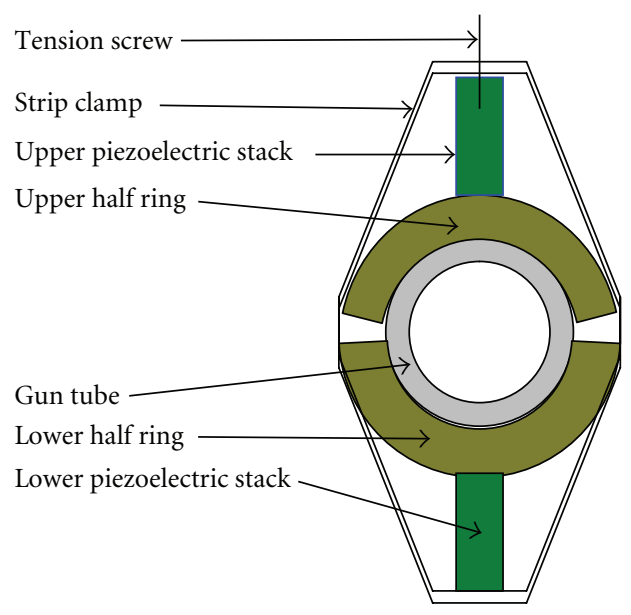

Figure 5: Double Piezoelectric stack configuration.

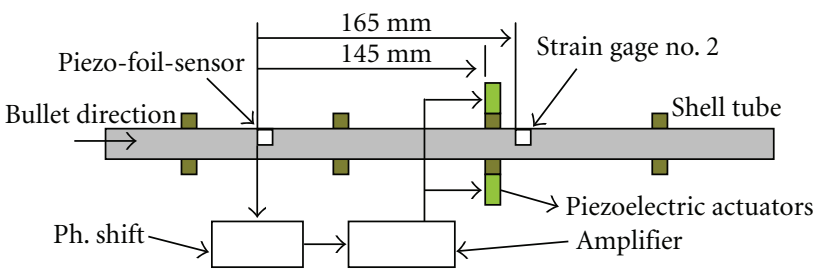

FIGURE 6: Piezoelectric stacks/feedforward control scheme.

3.2. Feedforward Control Elements Representation. The control circuit scheme is shown in Figure 6, of type feedforward; it is composed of piezoelectric foil pressure sensor located at distance $\times 1(165 \mathrm{~mm})$ upstream of the strain gage of location number 2 , and at distance $\times 2(145 \mathrm{~mm})$ upstream the piezoelectric stack actuator. The output signals are phase shifted and amplified, then feed the piezoelectric stacks, which are located at distance $\times 3(20 \mathrm{~mm})$ upstream the strain gage of location number 2 . The sensor has a time advance of $\Delta t 1$ (0.391 milliseconds) and the system (phase shifter, amplifier, and piezoelectric stacks) has a time lag of $\Delta t 2$ ( 0.372 milliseconds), so for ideal operating case the two times should be equal, or $\Delta t 2<\Delta t 1$ by few percent. By this way the actuators will have sensible impact on the tube vibrations; the phase can be adjusted by using phase shifter. The piezoelectric stack control setup view picture is shown in Figure 7.

3.3. Experimental Measurements and Results. The measurements are carried out at two operating helium pressures, 1600 and $2000 \mathrm{psi}$, and the controller (piezo-stack) is installed very close to location number 2 on the gun tube, as indicated in part 1 [16]. The expected deforming vibration due to these pressures ranges between 7.2 and $25 \mathrm{kHz}$, Part 1 [16], that is, far enough from the first mode frequency of the piezoelectric stack $(64 \mathrm{kHz})$, as shown in Figure 2.

3.3.1. Measurements at Pressure Level of 1600 psi. The time resolved measurement of plain tube is shown in Figure 8(a), and that of the arrangement when the control is turned

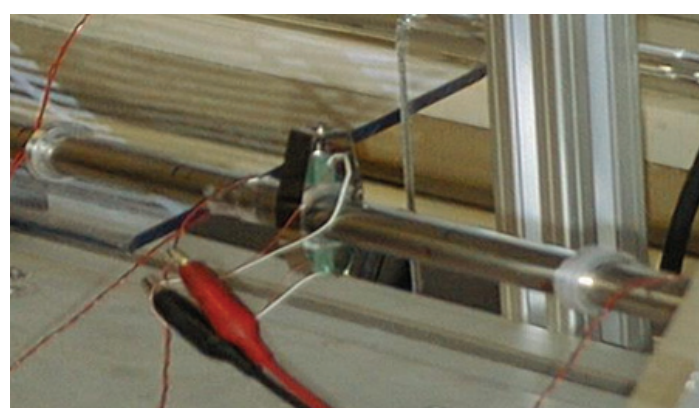

Figure 7: Piezoelectric stack control view picture.

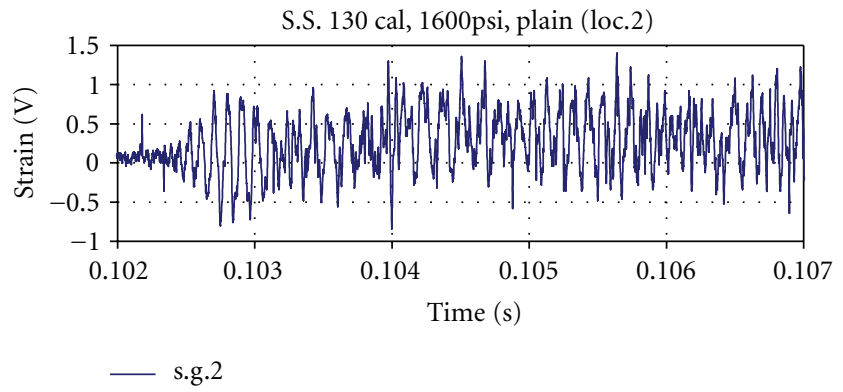

(a)

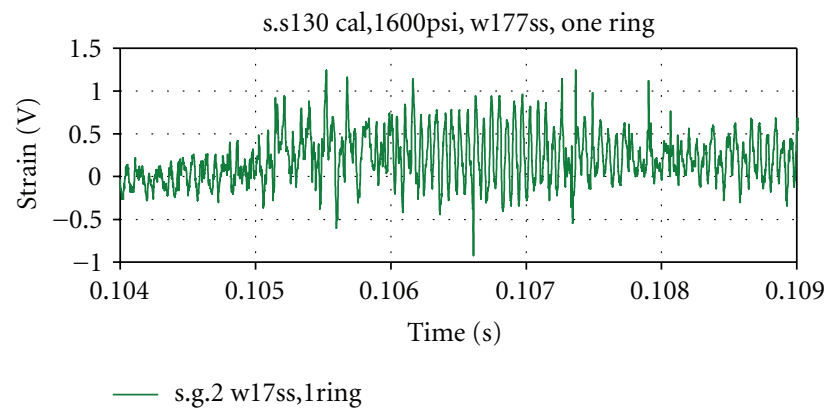

(b)

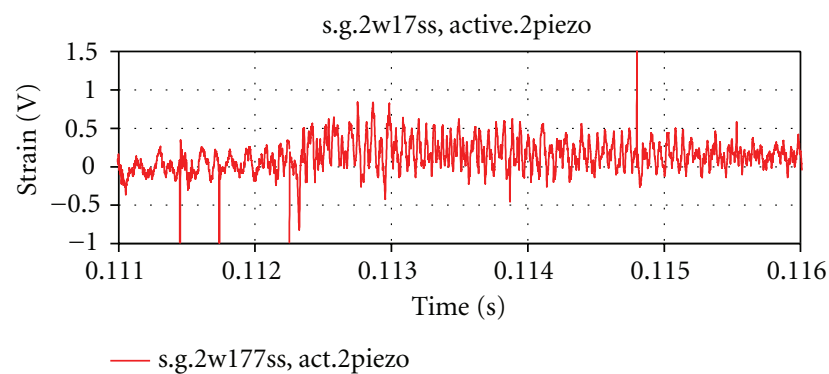

(c)

FIgure 8: (a) Output signal at location number 2 of plain tube at 1600 psi. (b) Output signal at location number 2 of tube with 17 single stiffeners. (c) Output signal of location number 2 with 17 single stiffeners and with active control at 1600 psi.

off, which is equivalent to the stiffened tube; is shown in Figure $8(\mathrm{~b})$, and the active controlled time domain signals is shown in Figure 8(c). A time domain comparison of active and stiffened tube, is shown in Figure 9, and the comparison analysis of the frequency domains is shown in Figure 10. 


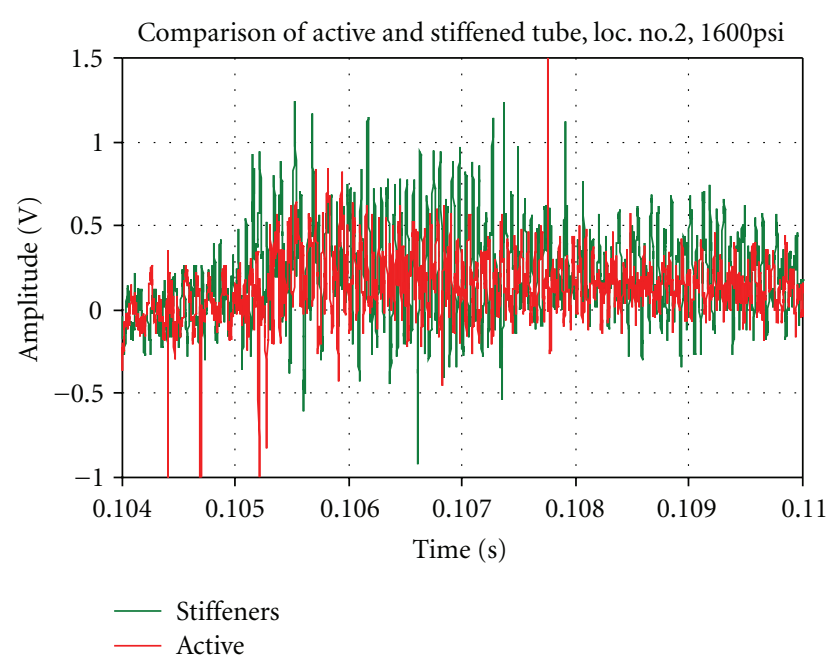

FIgURE 9: Time domain comparison between active and stiffened tube at location no. 2 at operating pressure 1600 psi.

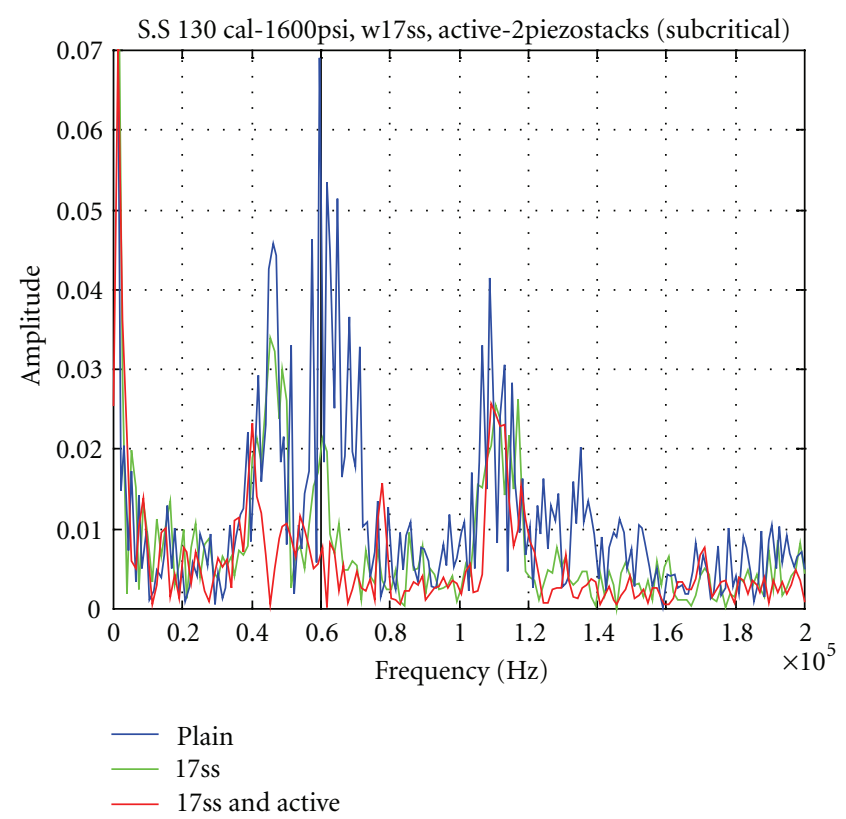

FIGURE 10: Frequency domain comparison between plain, stiffened tube, and with active piezo-stack control.

The attenuation ratio due to using active piezoelectric stack is attained to $33 \%$, at vibration mode of $7.2 \mathrm{kHz}$ and $48 \%$ at vibration mode of $9.5 \mathrm{kHz}$ for pressure level of 1600 psi. The effect of active control is decreased at higher vibration modes.

3.3.2. Measurements at Pressure Level of 2000 psi. The time domain measurement of the plain tube at pressure level of 2000 psi is shown in Figure 11(a) and that of the stiffened tube with piezo-stack arrangement without control is shown in Figure 11(b), and the controlled time resolved signal is shown in Figure 11(c). The frequency domain comparison is shown in Figure 12. A comparison of the piezoelectric foil

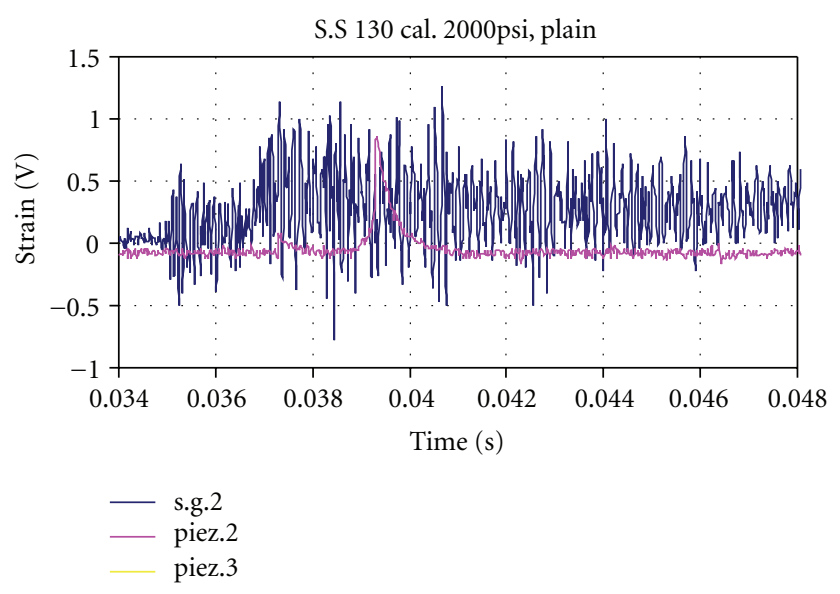

(a)

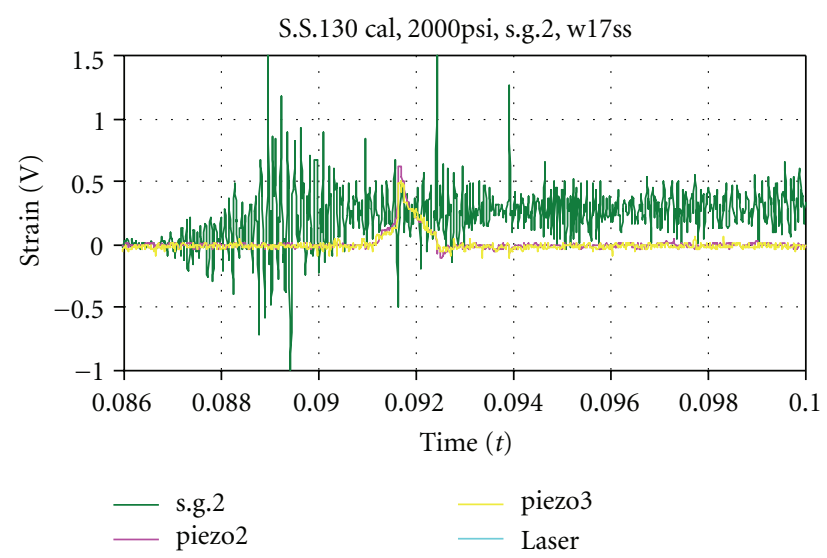

(b)

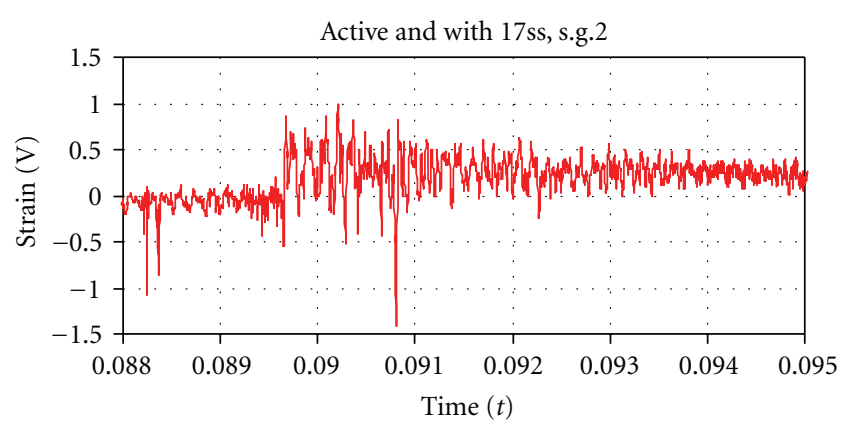

- 2bullet,s.g.2

(c)

Figure 11: (a) Output signal at location number 2 of plain tube at 2000 psi. (b) Output signal at location number 2 of tube with 17 single stiffeners at 2000 psi. (c) Output signal of location number 2 with 17 single stiffeners and with active control at $2000 \mathrm{psi}$.

sensor and amplifier output signals (piezo-stqack loading signal or the control effort) is shown in Figure 13, at amplifier gain factor of 2 .

The radial strain vibration is attenuated by using the active piezoelectric control by a ratio of $46 \%$ at vibration mode of $7.2 \mathrm{kHz}$ and $65 \%$ at $9.5 \mathrm{kHz}$. The attenuation ratio is increased at higher pressure level of 2000 psi than at pressure 
S.S 130 cal-1600psi, w17ss, active-2piezostacks (subcritical)

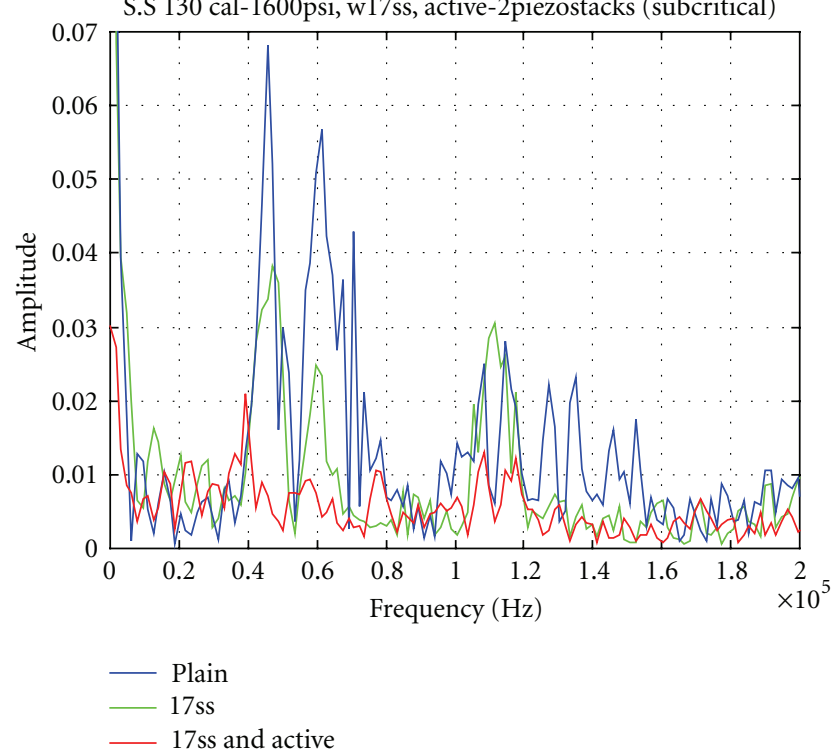

FIGURE 12: Frequency domain comparison between plain, stiffened tube, and with active control at 2000 psi.

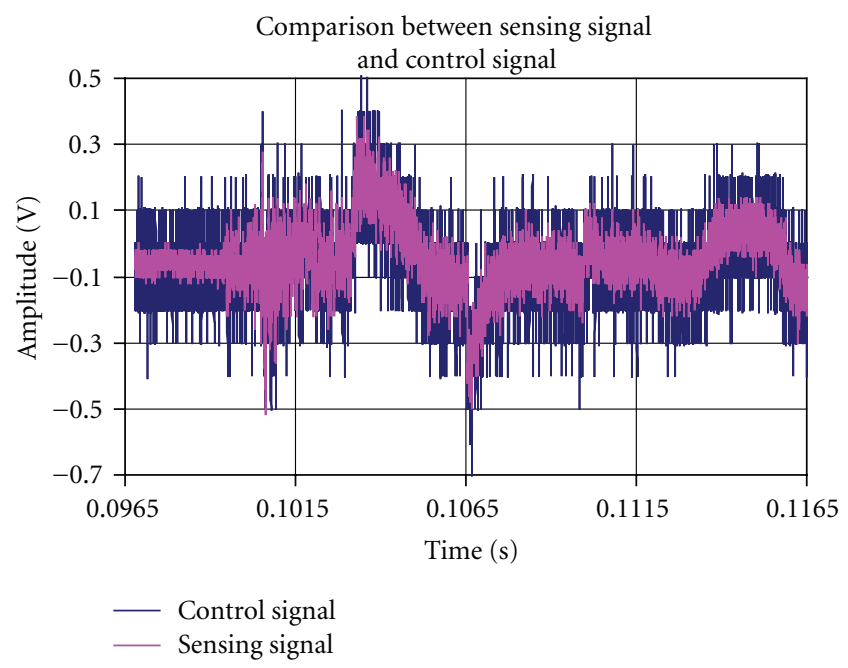

FIGURE 13: Comparison between piezoelectric sensor and amplified signals at amplifier gain factor of 2 .

level of 1600 psi, by a value of $40 \%$ for the first mode and by $35 \%$ for the second mode of vibrations. The frequency is shifted to lower values by about $13 \%$. This due to increasing the control effort nonlinearly with strain deformations which are occurred at the two pressure levels of the first and second experiments; consequently, the control signal is magnified sharply.

\section{Conclusion}

A cylindrical shell is actively controlled by using piezoelectric stacks for attenuating the radial circumferential vibrations due to moving pressure propelling mass.
A feedforward control scheme is designed and constructed by using piezoelectric foil sensor to predict in advance the incoming dynamics vibration and piez-stacks actuators.

The control system is checked at two pressures levels; first pressure level is $1600 \mathrm{psi}$ and the second pressure level is 2000 psi. The attenuation ratio is predicted at two modes of low-frequency vibrations.

At first mode of vibration, $7.2 \mathrm{kHz}$, the attenuation ratio is found to be about $33 \%$ and $46 \%$ at pressure levels of 1600 psi and 2000 psi, respectively.

And at second mode of vibration, $9.5 \mathrm{kHz}$, the attenuation ratio is found to be about $48 \%$ and $65 \%$ at pressure levels of 1600 psi and 2000 psi, respectively. At higher modes of vibrations the attenuation effect decreases to lower ratios. The frequency is shifted to lower values by about $13 \%$.

The frequency domain comparison for the two pressure levels indicates that the stability is satisfied and no spill over occurred.

\section{References}

[1] M. Z. Kiehl and C. P. T. W. Jerzak, "Modeling of passive constrained layer damping as applied to a gun tube," Shock and Vibration, vol. 8, no. 3-4, pp. 123-129, 2001.

[2] C. D. Johnson and D. A. Kienholz, "Finite element prediction of damping in structures with constrained viscoelastic layers," AAIA Journal, vol. 20, no. 9, pp. 1284-1290, 1982.

[3] D. J. McTavish and P. C. Hughes, "Modeling of linear viscoelastic space structures," Journal of Vibration and Acoustics, vol. 105, pp. 103-110, 1993.

[4] D. H. Golla and P. C. Hughes, "Dynamics of viscoelastic structures-a time-domain finite element formulation," Journal of Applied Mechanics, vol. 52, pp. 897-906, 1985.

[5] R. A. DiTaranto and W. Blasingame, "Composite damping of vibrating sandwich beams," Journal of Engineering for Industry, 1967.

[6] D. J. Mead and S. Markus, "The forced vibration of a threelayer, damped sandwich beam with arbitrary boundary conditions," Journal of Sound and Vibrations, vol. 10, no. 2, pp. 163-175, 1969.

[7] J. Ro, K. S. El-Din, and A. Baz, "Vibration control of tubes with internally moving loads using active constrained layer damping," in Proceedings of ASME Annual Meeting, vol. 223, pp. 1-11, Dallas, Tex, USA, November 1997.

[8] Y.-G. Sung, "Modeling and control with piezoactuators for a simply supported beam under a moving mass," Journal of Sound and vibration, vol. 250, no. 4, pp. 617-626, 2002.

[9] M. Ruzzene and A. Baz, "Dynamic stability of periodic shells with moving loads," Journal of Sound and Vibration, vol. 296, no. 4-5, pp. 830-844, 2006.

[10] M. Ruzzene and A. Baz, "Response of periodically stiffened shells to a moving projectile propelled by an internal pressure wave," Mechanics of Advanced Materials and Structures, vol. 13, no. 3, pp. 267-284, 2006.

[11] O. J. Aldraihem and A. Baz, "Moving-loads-induced instability in stepped tubes," Journal of Vibration and Control, vol. 10, no. 1, pp. 3-23, 2004.

[12] O. J. Aldareirhem and A. Baz, "Dynamic stability of periodic stepped beams under moving loads," Journal of Sound and Vibration, vol. 250, no. 2, pp. 835-848, 2002. 
[13] R. N. Miles and P. G. Reinhall, "An analytical model for the vibration of laminated beams including the effects of both shear and thickness deformation in the adhesive layer," Journal of Vibration, Acoustics, Stress, and Reliability in Design, vol. 108, pp. 56-64, 1986.

[14] E. L. Kathe, "MATLAB modeling of non-uniform beams using the finite element method for dynamic design and analysis," Tech. Rep. ARCCB-TR-960 10, US Amy Armaments Research, Development and Engineering Center; Close Combat Armaments Center, Benèt Laboratories, Watervliet, NY, USA.

[15] M. J. Lam, W. R. Saunders, and D. J. Inman, "Modeling active constrained layer damping using Golla-Haughes-McTavish approach," in Smart Structures and Materials 1995: Passive Damping, vol. 2445 of Proceedings of SPIE, pp. 86-97, San Diego, Calif, USA, March 1995.

[16] K. M. S. Eldalil and A. M. S. Baz, "Dynamic stability of cylindrical shells under moving loads by applying advanced controlling techniques Part 1-Using Periodic Stiffeners," in Advanced Materials for Application in Acoustics and Vibration, Cairo, Egypt, January 2009.

[17] G. E. Martin, "Vibrations of coaxially segmented longitudinally polarized ferroelectric tubes," The Journal of the Acoustical Society of America, vol. 36, no. 8, pp. 1496-1506, 1964.

[18] G. E. Martin, "On the theory of segmented electromechanical systems," The Journal of the Acoustical Society of America, vol. 36, no. 7, pp. 1366-1370.

[19] S. Sherrit, S. P. Leary, Y. Bar-Cohen, B. P. Dolgin, and R. Tasker, "Analysis of the impedance resonance of piezoelectric stacks," in Proceedings of the IEEE Ultrasonics Symposium, vol. 2, pp. 1037-1040, San Juan, Puerto Rico, October 2002.

[20] D. E. Seborg, T. F. Edgar, and D. A. Mellichamp, Process Dynamics and Control, John Wiley \& Sons, New York, NY, USA, 1989. 

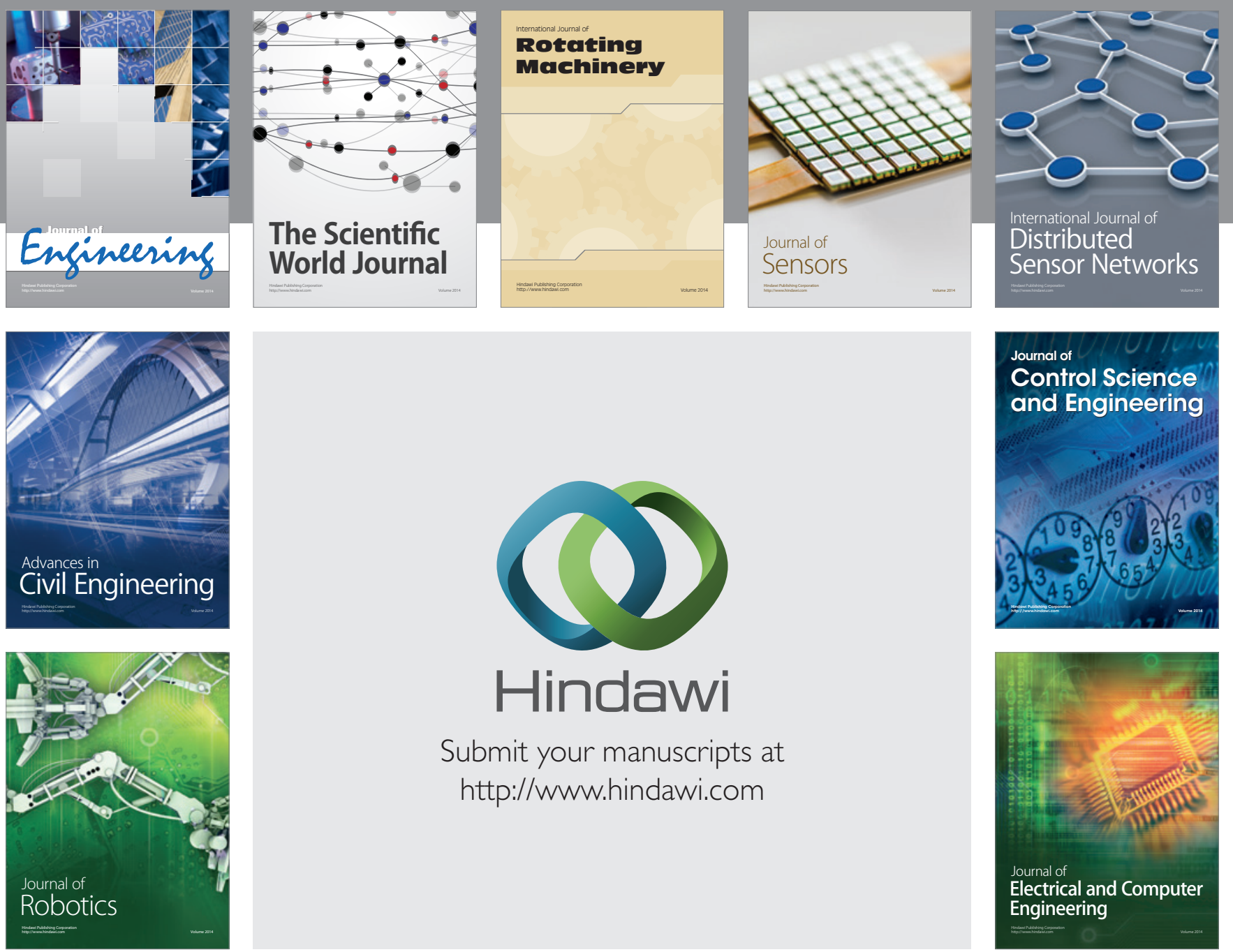

Submit your manuscripts at

http://www.hindawi.com
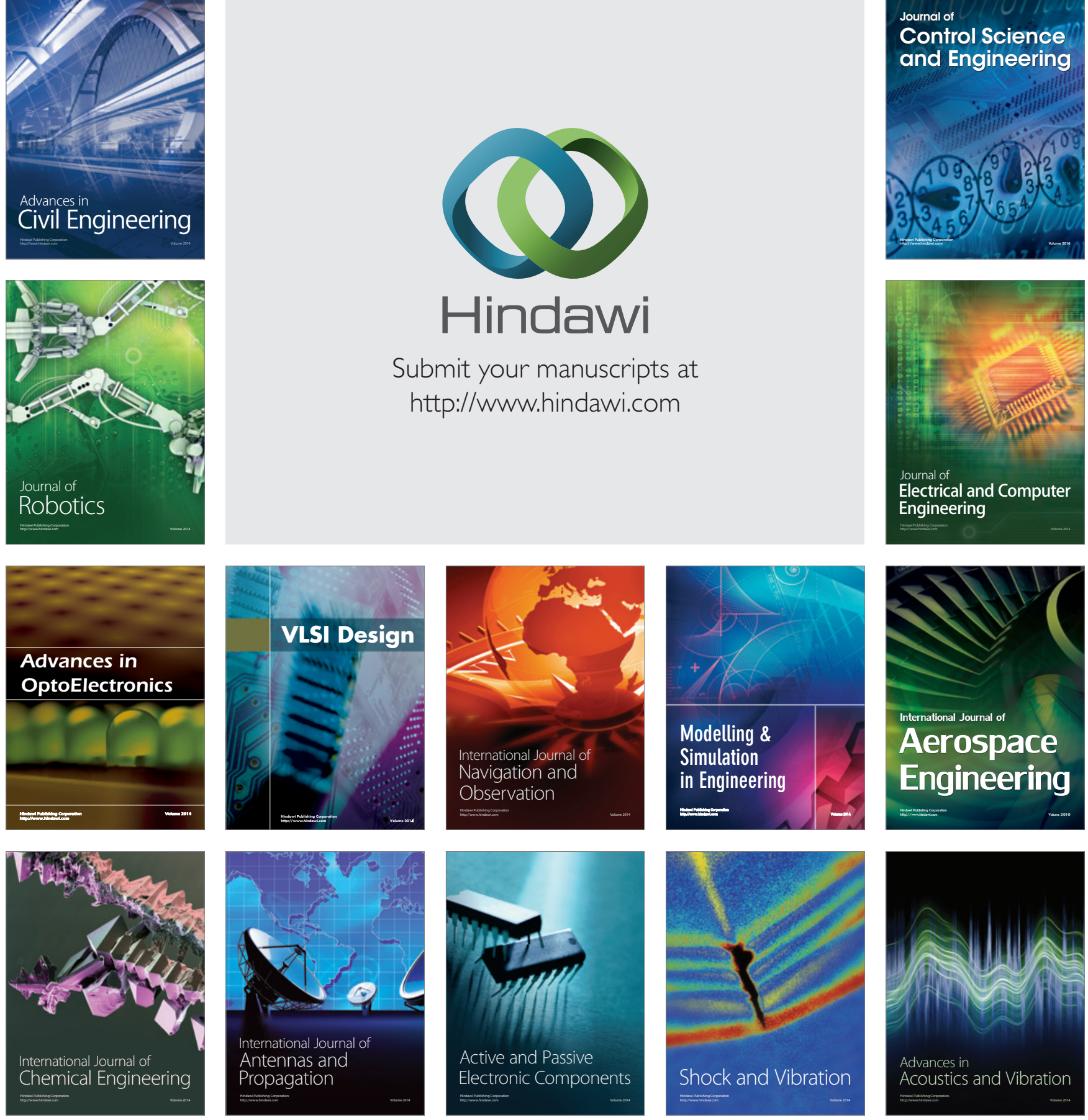